\title{
Evaluation of laboratory methods for cystic fibrosis carrier screening: reliability, sensitivity, specificity, and costs
}

\author{
Zosia H Miedzybrodzka, Zhikang Yin, Kevin F Kelly, Neva E Haites
}

\begin{abstract}
We report a comparative evaluation of three different laboratory methods for screening large numbers of mouthwash DNA samples for common cystic fibrosis mutations. Sensitivity, specificity, and costs of ARMS (allele refractory mutation detection system), dot blotting, and a deletion/digest/PAGE method (multiplex PCR of exons 10 and 11, digest with HincII followed by polyacrylamide gel electrophoresis (PAGE)) were assessed. ARMS was the most reliable and sensitive method and so was considered more suitable than the cheaper deletion/digest/ PAGE. As well as being less reliable than ARMS, the dot blotting method assessed was considerably more costly. ARMS was the best laboratory method for CF screening tested.
\end{abstract}

(f Med Genet 1994;31:545-550)

University of

Aberdeen Department of Obstetrics and

Gynaecology,

Aberdeen, UK

Z H Miedzybrodzka

University of

Aberdeen Department

of Medicine and

Therapeutics,

Aberdeen, UK

Z H Miedzybrodzka

N E Haites

University of

Aberdeen Health

Services Research

Unit, Aberdeen, UK

Z H Miedzybrodzka

University of

Aberdeen Department

of Molecular and Cell

Biology, Aberdeen, UK

$Z$ Yin

K F Kelly

N E Haites

Correspondence to $\mathrm{Dr}$ Miedzybrodzka, Medical Genetics, Medical School, Foresterhill, Aberdeen AB9 2ZD, UK.

Received 7 September 1993 Revised version accepted fo publication 2 February 1994 than one mutation simultaneously (multiplexing) are more efficient in use of labour and reagents. Such multiplex mutation detection can be performed by dot blotting methods, by
Population carrier screening programmes and routine diagnostic laboratories would from a mutation detection system uses a minimal amount of labour and is technically reliable, sensitive, and specific without a combination of deletion detection and restriction enzyme digest, or by using an ARMS system. ${ }^{8-10}$

We have performed a comparative assessment of the technical reliability, sensitivity, specificity, and costs of three types of mutation detection to find the best method for population CF screening.

\section{Methods}

The Cellmark ARMS system tests simultaneously for the mutations $\Delta F 508$, G $551 D$, $\mathrm{G} 542 \mathrm{X}$, and $621+1(\mathrm{G} \rightarrow \mathrm{T}){ }^{8}$ PCR is performed in two tubes, one tube containing mutation specific primers for G551D, G542X, and normal site specific primers for $\Delta \mathrm{F} 508$ and $621+1(G \rightarrow T)$, the second containing mutation specific primers for $\Delta F 508$ and $621+1(G \rightarrow T)$ and normal site specific primers for G551D and G542X. Test DNA ( $5 \mu 1$ mouthwash preparation) is added to each of these two tubes. After addition of oil the tubes are placed in the PCR block. Diluted Taq polymerase enzyme is added to each tube after two minutes ("hot start"), and then the PCR cycle is started. Products are detected by Nusieve agarose gel electrophoresis (fig 1).

Various multiplex dot blotting systems have been described. They use different techniques to allow hybridisation with several oligonucleotides to occur under the same conditions by using $T$ tails on oligonucleotide probes, the addition of tetramethylammonium chloride (TMAC), or differing lengths of oligonucleotide. $^{911}$ The reverse dot blot technique is usually used, with PCR product from each exon under study being labelled by incorporation in a multiplex PCR reaction. We chose to evaluate dot blotting by using the Inno-LiPA CF2 kit as an example (Innogenetics). ${ }^{9}$ This kit detects the mutations $\Delta \mathrm{F} 508, \Delta \mathrm{I} 507, \mathrm{G} 551 \mathrm{D}, \mathrm{G} 542 \mathrm{X}$, N1303K, W1282Xm 1717-1,G-A, and R553X. ${ }^{41213}$ Mouthwash DNA preparation $(5 \mu \mathrm{l})$ and $T a q$ polymerase are added to the PCR reagents provided, with biotin dUTP incorporated into PCR product as a label. After thermal cycling, PCR product from each patient is incubated with a membrane based strip, to which oligonucleotides of differing lengths have been bound. Two oligonucleotides are used for each mutation, one for the normal and one for the mutation sequence. Hybridisation is performed in a trough provided by the manufacturer. Streptavidin labelled alkaline phosphatase is then added which binds to the biotinylated PCR product. Incubation with a BCIP/NBT (bromochoro-indolyl phosphate/ nitroblue tetrazolium) chromogen results in a 


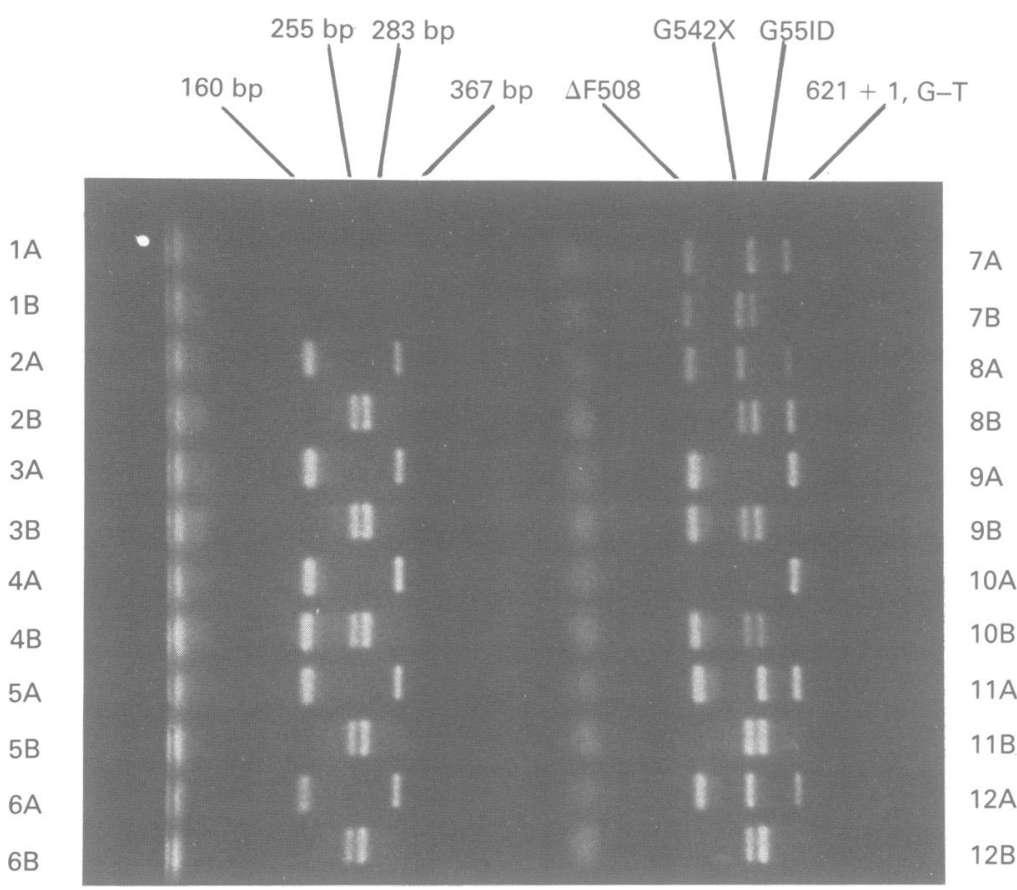

Figure 2 Dot blotting nylon strips. Strips 2, 3, 4, 6, and 8 show samples testing negative for the mutations under study. Note wild type "w" band for each mutation. Strips 1,5 , and 9 have an extra " $m$ " band corresponding to the mutant $\Delta F 508$ sequence ( $\triangle F 508$ carriers). Strip 7 G551D carrier, strip 10 R553X carrier. Strips 11 and $13 \Delta F 508$ homozygotes (note no wild type band). Strip 12 is $\triangle F 508 / G 542 X$ compound heterozygote, 14 is $\triangle F 508 / G 551 D$ compound heterozygote, 15 is $1717-1, G \rightarrow A$ carrier, 16 is $\Delta I 507$ carrier, 17 is $W 1282 X$ carrier. Strip 18 represents a $\triangle F 508 / N 1303 \mathrm{~K}$ compound heterozygote, 19 is no DNA control, 20 is wild type control.

purple/brown precipitate where PCR product has hybridised to oligonucleotides (fig 2).

The third method we evaluated combines deletion analysis with a restriction enzyme digest, allowing simultaneous detection of the mutations $\Delta \mathrm{F} 508, \Delta \mathrm{I} 507, \mathrm{G} 551 \mathrm{D}$, and R553X (deletion/digest/PAGE method). A standard PCR reaction is performed using primers flanking both exons 10 and 11 with mouthwash DNA (primers sequences from Shrimpton et $a l,{ }^{2}$ annealing temperature for PCR $58^{\circ} \mathrm{C}$ ). PCR product is digested with HincII then detected by PAGE. The mutations G551D and R553X destroy a HincII restriction site, $\Delta \mathrm{F} 508$ and $\Delta \mathrm{I} 507$ cause a smaller band (fig 3 ). ${ }^{10}$

\section{DNA EXTRACTION}

A total of 1808 mouthwash samples was obtained as part of our clinical study of CF carrier screening at Aberdeen Maternity Hospital antenatal clinic and were prepared for 


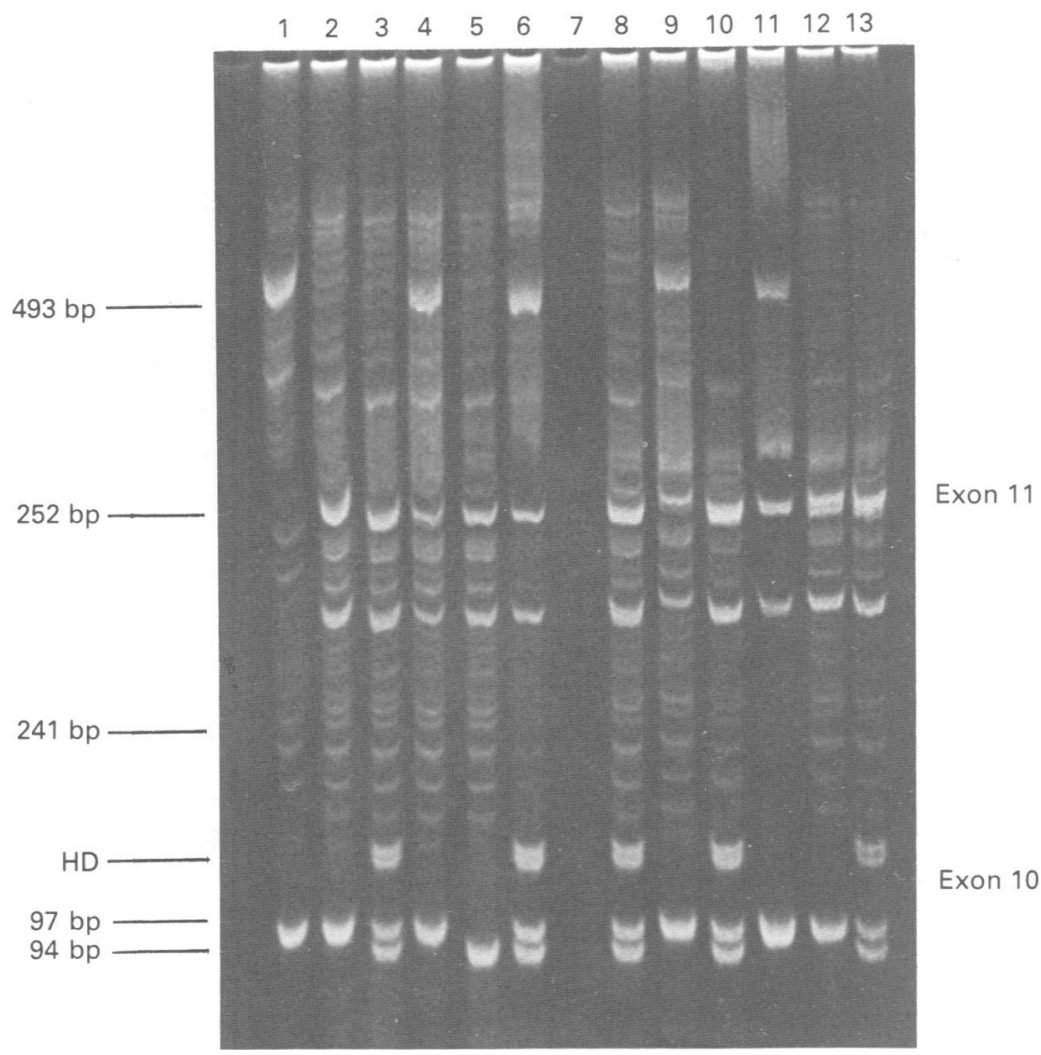

Figure 3 Deletion/digest/PAGE. 493 bp band is undigested exon 11 PCR product, $252 \mathrm{bp}$ and $241 \mathrm{bp}$ bands are products of exon 11 PCR product digest, $97 \mathrm{bp}$ band from undeleted exon $10 \mathrm{PCR}$ product, $94 \mathrm{bp}$ band indicates presence of deletion.
Heteroduplex analysis (bands at position $H D$ ) allows differentiation between $\triangle F 508$ and $\triangle I 507$ ( $\triangle F 508$ double heteroduplex band, $\triangle I 507$ single heteroduplex band). Lane 1 undigested control. Lanes 2 and 12 normal. Lanes 3, 8, 10, and 13 indicate $\triangle F 508$ carriers. Lanes 4, 9, and 11 G551D carriers. Lane 5 AF508 homozygote. Lane 6 $\triangle F 508 / G 551 D$ compound heterozygote. Lane 7 no DNA control.

analysis using the method recommended by Cellmark..$^{81415}$ DNA was extracted from affected persons' blood samples by the method of Kunkel et al..$^{16}$

\section{ARMS EVALUATION}

A total of 1808 mouthwash samples was tested using the Cellmark CF Mutation Detection ARMS system, as were 40 samples from affected persons. Analysis was performed by following the manufacturer's instructions. Testing was repeated if there were extra bands, faint bands, or absent bands, or if a carrier was detected.

DOT BLOTTING: INNO-LIPA CF2 KIT

This system was assessed by testing samples from the 55 carriers detected above, 16 partners' samples (previously tested negative), and 19 samples from affected persons. All these samples had been previously tested by ARMS. Testing was performed according to the manufacturer's instructions.

\section{DELETION/DIGEST/PAGE METHOD}

This method was used to test DNA from 59 carriers, 58 partners (previously tested negative), and 64 persons affected by $C F$, for $\Delta F 508$, G551D, $\Delta$ I507, and R553X. These samples had previously been tested using the other two methods. We are grateful to our colleagues at the Human Genetics Unit in Edinburgh for giving us further details of their published method. ${ }^{10}$

\section{COSTING}

The costs of consumables for each method of testing included the cost of unsupplied reagents required in addition to those supplied in the kits. As the Cellmark system is not commercially available, the anticipated cost was obtained from the manufacturer ( $£ 10$ to $£ 14$ per test, so $£ 12$ used in calculations). Time sheets were used to estimate labour costs for each method (only the labour specifically relevant to this project counted). Employment costs of $£ 12.08(\$ 17.73)$ per hour were used (cost of a grade B clinical scientist, spine point 9). Reagent and labour costs were calculated for five batches of each type of test. Record keeping time and reading of gels was included in our assessment. Mean cost for 100 samples was then calculated to allow comparability. Note that the optimum number of tests per batch varies for each method (table). US dollar (\$) equivalent prices were calculated using an exchange rate of $\$ 1.4679$ to the pound $(f)$ sterling.

In addition, the costs of producing and posting reports were estimated (secretarial time was 
Comparison of different molecular methods for CF carrier screening

\begin{tabular}{|c|c|c|c|}
\hline System & Cellmark ARMS & $\begin{array}{l}\text { Dot blot } \\
\text { (Inno-LiPA CF2) }\end{array}$ & Deletion/digest/PAGE \\
\hline Standard batch size (inc controls) & 24 & 20 & 40 \\
\hline $\begin{array}{l}\text { Costs (100 tests) } \\
\text { Kit } \\
\text { Other consumables } \\
\text { Labour } \\
\text { Mouthwash DNA preparation (100) }\end{array}$ & $\begin{array}{l}f_{1200 *} \\
f^{48} \\
f_{239.80} \\
f_{160.05}\end{array}$ & $\begin{array}{l}£ 2394.90 \dagger \\
£ 148.80 \\
£ 543.60 \\
£ 160.05\end{array}$ & $\begin{array}{l}\bar{£} 218 \\
£ 249.75 \\
£ 160.05\end{array}$ \\
\hline Total lab cost (100 tests) & $\begin{array}{l}f_{(\$ 2418.90)} 1647.85 \\
(\$ 2\end{array}$ & $\begin{array}{l}£ 3247.45 \\
(\$ 4766.95)\end{array}$ & $\begin{array}{l}\underset{f 627.80}{(\$ 921.55)}\end{array}$ \\
\hline $\begin{array}{l}\text { Repeat rate } \\
\text { Lab cost per test inc repeats and } 4 \\
\text { controls per batch } \\
\text { Lab cost per test inc repeats, controls, } \\
\text { reporting, and overheads } \\
\text { No of mutations detected } \\
\text { Proportion of Scottish mutations detected }\end{array}$ & $\begin{array}{l}4 \cdot 6 \% \\
(85 / 1851) \\
f_{20.69} \\
(\$ 30.37) \\
£ 23.17 \\
(\$ 34.01) \\
4 \\
81 \cdot 4 \%\end{array}$ & $\begin{array}{l}7 \cdot 2 \% \\
(7 / 97) \\
f 41.30 \\
(\$ 60.62) \\
f 43.78 \\
(\$ 64.26) \\
8 \\
83 \%\end{array}$ & $\begin{array}{l}45 \% \\
(102 / 225) \\
\text { f9.75 } \\
(\$ 14.31) \\
f_{(\$ 12.23} \\
(\$ 17.95) \\
4 \\
77.6 \%\end{array}$ \\
\hline
\end{tabular}

* Anticipated cost

+24000 Belgian francs.

costed at $£ 6.37$ (\$9.35) per hour including breaks and holidays). True overhead costs are difficult to calculate; there might be little extra expenditure if the staff of an existing, equipped laboratory was increased, but a new building specifically for screening would substantially increase overheads. The overhead costs for a screening programme employing one extra scientist have been estimated by dividing the cost of upkeep of our local laboratory block by the number of people working within it. However, if the costs quoted below are used to cost a screening programme, local overheads and capital costs should be estimated, together with the costs of depreciation of equipment, in the context of existing facilities.

\section{Results}

MOUTHWASH PREPARATION

Preparation of 100 mouthwashes for PCR takes $10 \cdot 7$ hours $(£ 129.25 / \$ 189.75)$, if time for record keeping is included. The cost of consumables is $£ 30.80$ (\$45.20), including the cost of the sampling kit (total cost to prepare 100 mouthwashes $=£ 160.05 / \$ 234.95)$.

\section{ARMS}

We found this system fairly simple to use although interpretation of results became easier with experience. A part time scientist (20 hours) was able to analyse 102 samples in a two week period, but was unable to do the mouthwash preparation (see table for further details of costing).

\section{Sensitivity and specificity}

Early on in our use of this system, there was one false positive. The G542X mutation specific band appeared, although it was fainter than its control. When the test was repeated on two occasions, no mutation specific band was present and direct sequencing confirmed that DNA tested had the wild type sequence at the G542X site. When this result was reviewed when we had increased experience with the system, we considered that result should initially have been interpreted as a technical failure. If a mutation specific band is fainter than other bands, the test must be repeated. We check all carrier results with a repeat sample to minimise sampling and laboratory errors. We did not detect any ARMS false negatives with the other two methods.

\section{Technical reliability}

Technical failures occurred through tests needing to be repeated because of faint artefactual bands or missing internal control bands. The overall repeat rate was $4 \cdot 6 \%$. Forty percent of the technical failures had faint artefactual bands and control bands were missing in the rest. Such problems rarely persisted when testing was repeated; repeat sampling was only necessary in $0.007 \%$ of cases. Our experience suggests that if one lane fails, or if there are faint bands in both lanes, repeat testing may yield satisfactory results (successful in $68 \%$ of cases). If no bands appear, a repeat sample should be requested (repeat testing is only successful in $18 \%$ of cases). The mean number of technical failures per batch of 20 samples (and four controls) was 0.73 , the standard deviation being 1.32. About half of the reported failures occurred in the first two tests in a batch, with faint extra bands in the mutant G551D and G542X positions. This type of problem has been shown to arise if there is excess $T a q$ polymerase enzyme (S Little, personal communication). Excess enzyme may be added to some samples if it is not mixed thoroughly with dilution buffer before addition.

\section{DOT BLOTTING-INNO-LIPA CF2 KIT}

This sytem was less robust than ARMS and required slightly more development time to get diagnostic quality results than ARMS did. The product information states that a $1^{\circ} \mathrm{C}$ difference in hybridisation temperature will cause nonspecific hybridisation. Two waterbaths are necessary as hybridisation ovens do not conduct heat sufficiently well into the individual troughs provided with the kit. Although no false positives were detected in our assessment, most of the technical failures were because of nonspecific hybridisation, which could be interpreted as false positives. As with the ARMS system, we suggest that unless all bands are of 
equal intensity a test should be repeated. Not enough tests were performed to comment on batch to batch variation in technical reliability.

\section{DELETION/DIGEST/PAGE METHOD}

Despite spending some time altering the reaction conditions for this method, problems visualising the undigested exon 11 band persisted, as did spurious bands, requiring a very high test repeat rate (at least $45 \%$ ). Two out of nine G551D carriers might have been undetected had we relied upon this system alone (two false negatives) and, therefore, although we know that the system works well in other hands, we did not persist with the technique.

\section{COST OF REPORTING AND OVERHEADS}

This was the same whatever test method being used. To report 100 tests results, a scientist spent 10 hours recording results and preparing and signing reports $(£ 120.80 / \$ 604)$ and a secretary took five hours to post results $(£ 31.86)$. Supervision by a senior scientist (grade 14-16) took one hour, $(£ 13.00$ per hour $\$ 19.08)$. Stationery costs for five copies of 100 reports, with results being posted to both patient and GP were $£ 55.51$ ( $\$ 81.48$; paper and printing $£ 10.71$, envelopes $£ 6.80$, postage $£ 38.00$ ). Thus overall reporting cost for 100 tests was $£ 222.17$ (\$326.12).

We have estimated our own local overheads by calculating the total cost of running the laboratory block (including rental) by the number of staff employed. This is $£ 595$ per person per year; thus the overheads for a 40 hour week (100 samples) would be $£ 25.87$ (\$37.97). An estimate for the total overhead and reporting cost for 100 samples is therefore $£ 248.04$ $(\$ 364.10)$.

\section{Discussion}

Although the deletion/digest/PAGE method is the cheapest method, we did not find it reliable enough for routine large scale clinical use. Because of the high repeat rate and the possibility of incomplete digestion of PCR products giving a false negative result, we felt it was unsuitable for a prenatal screening programme when results are required quickly. On balance, we consider the Cellmark ARMS system to be the best method tested, dot blotting being less technically reliable as well as more costly. The marginal cost of detecting an extra $1.6 \%$ of mutations in the Scottish population using the dot blotting kit would be $£ 12.88$ per test (\$18.91). Nevertheless, we consider that the Innogenetics system may be useful for testing $\mathrm{CF}$ sufferers once common mutations have been excluded.

Both operator and interpretative experience improve results for all systems. We consider that technical reliability is dependent upon DNA sample quality, which is difficult to control in a clinical situation. Challenge experiments using mouthwash samples provided by volunteers in our laboratory have shown that eating or drinking soon before mouthwashing causes technical failure.

Estimated costs of the laboratory side of CF carrier screening are presented. In planning a genetic screening programme it is essential to cost the clinical and counselling resources required fully, both pretest and for detected carriers. The difficulty of realistically assessing local overheads has been addressed above. The staff costs were based on grades of staff that would be used for clinical tests in our service laboratory. Other centres might consider it more appropriate to use an experienced technician for the assays, although more supervision might be required, especially for reporting. Urgent samples made little impact on the running of our programme because testing was being done every second day, so extra batches were not required. If running a prenatal screening service, holiday cover is essential for all staff. This is accounted for in the costing assuming that salaries of replacements are the same as those of the regular staff.

The cost of commercial CF kits reflect high licensing charges for the use of PCR and the CF gene (Toronto Sick Children's Hospital). The position of individual laboratories regarding these charges is as yet unclear in the UK, although it seems likely that "home made" systems will prove much cheaper. It may be that the high licensing charges will limit the availability of carrier testing.

We are grateful to Ruth Adamson, Dorothy Tay, and all the patients and staff of Aberdeen Maternity Hospital for sample collection, to Gail Rettie, Alasdair Williamson, and Mark Davidson for ARMS analysis, and to Drs Steve Little and Richard Axton for helpful advice. We thank Cellmark Diagnostics for the provision of ARMS kits. This study was funded by the Scottish Hospitals Endowments Research Trust and made possible by studies funded by the Wellcome Trust and Grampian Health Board. ZM is currently funded by the Scottish Office Home and Health Department. The opinions expressed are those of the authors and not necessarily those of the funding bodies.

1 Kerem B, Rommens JM, Buchanan JA, et al Identification of the cystic fibrosis gene: genetic analysis. Science 1989; of the cystic

2 Shrimpton AE, McIntosh I, Brock DJ. The incidence of different cystic fibrosis mutations in the Scottish population: effects on prenatal diagnosis and genetic counselling. f Med Genet 1991;28:317-21.

3 Miedzybrodzka ZH, Dean JCS, Russell G, et al. Prevalence of cystic fibrosis mutations in the Grampian region of Scotland. F Med Genet 1993;30:316-17

4 Kerem B, Zielenski J, Markiewicz D, et al. Identification of mutations in regions corresponding to the two putative nucleotide (ATP)-binding folds of the cystic fibrosis gene. Proc Natl Acad Sci USA 1990;87:8447-51.

5 Schwarz M, Summers C, Heptinstall L, et al. A deletion mutation of the cystic fibrosis transmembrane conductance regulator (CFTR) locus: delta I507. Adv Exp Med Biol 1991;290:393-8.

6 Cutting GR, Kasch ML, Rosenstein BJ. A cluster of cystic fibrosis mutations in the first nucleotide binding fold of the cystic fibrosis conductance regulator protein Nature 1990;346:366-9.

7 Zielenski J, Bozon D, Kerem B, et al. Identification of mutations in exons 1 through 8 of the cystic fibrosis transmembrane conductance regulator (CFTR) gene. Genomics 1991;10:229-35.

8 Ferrie RM, Schwarz MJ, Robertson N, et al. Development, multiplexing and application of ARMS tests for common mutations in the CFTR gene. Am $\mathcal{f}$ Hum Genet 1992;51:251-62.

9 Cuppens H, Buyse I, Baens M, et al. Simultaneous screening for 11 mutations in the CFTR gene by multiplex ing for 11 mutations in the CFTR gene by multiplex
amplification and reverse dot-blot. Mol Cell Probes 1992; 6:33-9.

10 Mennie ME, Gilfillan A, Compton M, et al. Prenatal screening for cystic fibrosis. Lancet 1992;340:214-16.

11 Serre JL, Taillandier A, Mornet E, et al. Nearly $80 \%$ of cystic fibrosis heterozygotes and $64 \%$ of couples at risk 
may be detected through a unique screening of four mutations by ASO reverse dot blot. Genomics 1991; 11:1149-51.

12 Osborne L, Knight R, Santis G, et al. A mutation in the second nucleotide binding fold of the cystic fibrosis gene. Am $\mathcal{f}$ Hum Genet 1991;48:608-12.

13 Vidaud M, Fanen P, Martin J, et al. Three mutations in the CFTR , Fanen P, Martin J, er al. Three mutations in the CFTR gene in French cystic fibrosis patients: identification by denaturing gel electrophoresis. Hum Genet
14 Miedzybrodzka Z, Haites N, Hall M, et al. Antenatal carrier screening for cystic fibrosis: whether, when and how? Paediatr Perinat Epidemiol 1993;7:368-75.

15 Lench N, Stainer P, Williamson R. Simple non-invasive method to obtain DNA for gene analysis. Lancet 1988;1:1356-8.

16 Kunkel LM, Smith KD, Boyer SH, et al. Analysis of human $\mathrm{Y}$ chromosome specific reiterated DNA in chrohuman Y chromosome specific reiterated DNA in chro-
mosome variants. Proc Natl Acad Sci USA 1977;74:1245-9. 